\title{
Do patients with chronic noncancer pain accept treatment of questionable benefit more readily than those who are pain free?
}

\author{
Mark K Simmonds MB ChB FRCA ${ }^{1}$, Saifee Rashiq BM BS DA MSc FRCPC ${ }^{1}$, \\ Philip Klemka MD FCFP'2, Alexander S Clanachan $\mathrm{PhD}^{3}$
}

\begin{abstract}
MK Simmonds, S Rashiq, P Klemka, AS Clanachan. Do patients with chronic noncancer pain accept treatment of questionable benefit more readily than those who are pain free? Pain Res Manage 2004;9(2):81-85.
\end{abstract}

BACKGROUND: The efficacy of some common, questionable chronic pain interventions has been debated and it is unclear why sufferers of chronic noncancer pain agree to receive them. This study attempts to determine if chronic pain sufferers characteristically more readily accept treatment with questionable benefit.

OBJECTIVES: This study aims to compare the strength of acceptance or rejection of a hypothetical, mock chronic pain treatment of debatable value by two groups of patients: those reporting chronic noncancer pain and those who are 'pain free'.

METHODS: A questionnaire proposing a hypothetical treatment for chronic pain was distributed to two groups: Group $1(n=160)$, patients attending a chronic pain centre, and Group $2(n=240)$, patients attending a family practice centre. Patients were asked to score their 'treatment acceptance' using a modified Likert scale. The treatment was based on the risks and benefits of epidural steroids. RESULTS: Ninety-three patients in Group 1 were eligible for inclusion in the 'chronic pain' group and 92 patients from Group 2, for the 'pain free' group. The median scores were identical at +3 ; nonparametric testing revealed no significant difference between the groups in their acceptance of the treatment.

CONCLUSIONS: An analogue study such as this removes the potential bias of clinical interaction with a physician, but lacks some reality. Nonetheless, the results from this study did not support the hypothesis that patients with chronic noncancer pain accept treatment of questionable benefit more readily than those who are 'pain-free'.

Key words: Decision making; Epidural; Injections; Intractable; Pain
Les patients souffrant de douleurs non cancéreuses chroniques acceptent-ils un traitement aux bénéfices douteux plus facilement que ceux qui n'éprouvent pas de douleur?

HISTORIQUE : L'efficacité de certaines interventions courantes mais douteuses contre la douleur chronique a été évaluée, et on ne sait pas exactement pourquoi les personnes souffrant de douleurs non cancéreuses chroniques acceptent de les subir. La présente étude vise à déterminer s'il est caractéristique que les personnes souffrant de douleurs chroniques acceptent plus facilement de tels traitements.

OBJECTIFS : La présente étude visait à comparer la conviction d'acceptation ou de rejet d'un simili-traitement contre la douleur chronique de valeur douteuse de deux groupes de patients : ceux qui souffrent de douleurs non cancéreuses chroniques et ceux qui ne ressentent aucune douleur.

MÉTHODOLOGIE : Un questionnaire proposant un traitement hypothétique de la douleur chronique a été distribué à deux groupes : le groupe 1 ( $n=160)$, composé de patients clients d'un centre de douleur chronique, et le groupe 2 ( $n=240)$, composé de patients clients d'un centre de pratique familiale. Ils ont été invités à évaluer leur « acceptation du traitement " d'après une échelle de Likert modifiée. Le traitement se fondait sur les risques et les bénéfices de stéroïdes périduraux.

RÉSULTATS : Quatre-vingt-treize patients du groupe 1 étaient admissibles dans le groupe de « douleur chronique » et 92 patients du groupe 2, dans le groupe «sans douleur ». Les scores médians étaient identiques à +3. Les tests non paramétriques ne révélaient aucune différence significative entre les groupes pour ce qui est de leur acceptation du traitement. CONCLUSIONS : Une étude analogique comme celle-ci évite les biais potentiels de l'interaction clinique avec le médecin mais ne reflète pas la réalité. Néanmoins, les résultats de la présente étude n'étayent pas l'hypothèse selon laquelle les patients souffrant de douleurs non cancéreuses chroniques acceptent un traitement aux bénéfices douteux plus facilement que ceux qui ne ressentent aucune douleur.
$T^{h}$ here is a requirement of physicians to be aware of the evidence for any treatment, practice according to this evidence and discuss the associated risks and benefits of the treatment with the patient (1). We are aware that some chronic pain treatments confer little benefit, with the possibility of significant risk, and the efficacy of some chronic pain interventions has been questioned (2). These interventions are widely available and accepted by patients, but we remain unclear as to why $(3,4)$. Underpinning the need to answer this question is the concern over escalating health care costs, and more specifically, there is a need to provide evidence that it is justified to fund the wealth of questionable treatments available for chronic pain in the marketplace. For example, in the United Kingdom, a recent survey indicated that $95 \%$ of pain centres will offer therapies with a questionable evidence base such as single shot epidural injections and transcutaneous electrical nerve stimulation.

${ }^{1}$ Department of Anesthesiology and Pain Medicine, Walter Mackenzie Health Sciences Centre, University of Alberta; ${ }^{2}$ The Grey Nuns Family

Medicine Centre, Grey Nuns Hospital, Cedars Professional Park; ${ }^{3}$ Department of Pharmacology, Faculty of Medicine and Dentistry,

University of Alberta, Edmonton, Alberta

Correspondence: Dr Mark K Simmonds, Department of Anesthesiology and Pain Medicine, 8.120 CSB, University of Alberta, Edmonton,

Alberta T6G 2G3. Telephone 780-407-8861 ext 223, fax 780-407-3200, e-mail mark.simmonds@ualberta.ca 


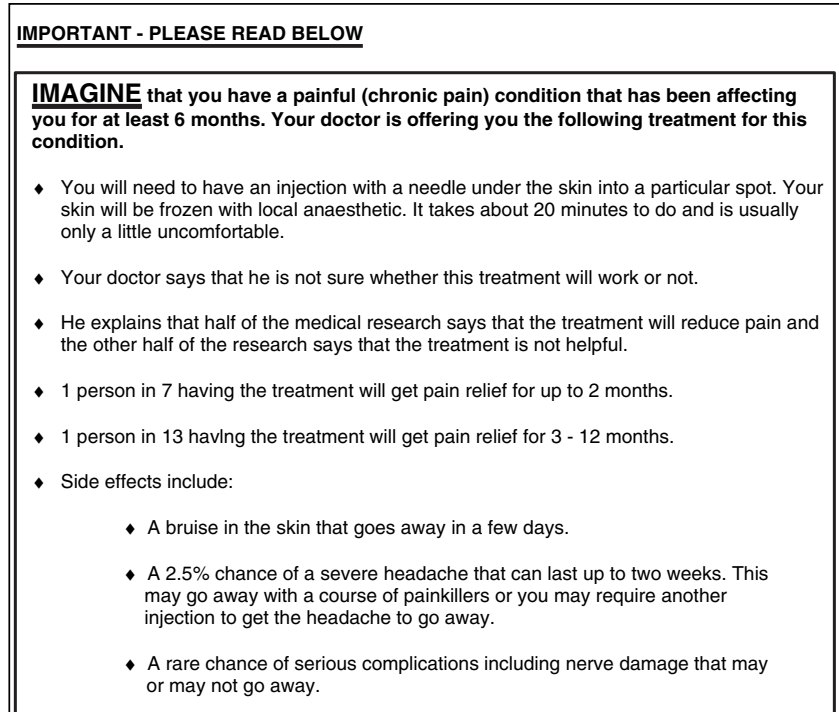

\section{QUESTION (Section A) EVERYONE TO COMPLETE}

On the basis of the above information say how strongly you are going to accept or reject the treatment by putting a circle around one of the numbers below.

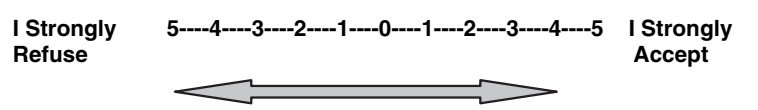

NB This scenario is in no way meant to imply a treatment that you should be seeking

QUESTIONS (Section B) EVERYONE TO COMPLETE

1. How old are you today (in Years) ? ................................ears.

2. Are you male or female? (Please Circle) Male Female

3. Which one of the $\mathbf{3}$ following groups would you put yourself into? PLEASE CHECK ONE BOX BELOW WITH A $\sqrt{ }$

A $\square$ I have had no pain problems over the last 6 months, including today (apart from brief pains that were minor and lasted only a day or two e.g. sore throat, sore muscles after exercise or a brief headache).

$\mathbf{B} \square$ I have had a severe, persistent pain condition for at least the last 6 months?

$C \square$ I do not fit into either of the above groups.

\section{** ONLY IF YOU HAVE CHECKED $\sqrt{ }$ GROUP $B$ above}

ANSWER THE FOLLOWING QUESTIONS 4 and 5

\section{How long have you suffered from pain (To the nearest Year) ? ......................... Years}

5. On a scale of 0 to $\mathbf{1 0}$ how would you rate your pain today? (Circle a number)

No Pain ～0----1----2----3----4----5----6----7----8----9----10 The most severe pain possible.

\section{EVERYONE PLEASE ANSWER BELOW}

6. Have you understood all the above questions?

YES NO (Please Circle)

Figure 1) Study questionnaire
Only $58 \%$ of clinics would offer outpatient pain management programs, despite evidence of their efficacy (5).

There is a multitude of physician and patient factors that influence a patient's treatment decision. Perhaps, for example, as health professionals, we may make an assumption that we are quite justified in attempting to alleviate pain and suffering through whatever means possible, sometimes even if the benefit is short-lived and the supporting evidence for the intervention debatable. We are already aware that patients with cancer receiving palliative chemotherapy are often willing to put up with significant side effects for modest benefit (6). In contrast, however, a recent study highlighted the finding that patients did not favourably view the risk benefit ratio of some widely accepted medical interventions (7). It is also possible that patients with chronic noncancer pain are characteristically, as a group, more willing to accept questionable treatment; unfortunately, the current paucity of literature to date on the subject of decision-making in the realm of chronic pain does not allow us to answer this question. This preliminary study explored the hypothesis that patients reporting chronic noncancer pain are intrinsically more ready to accept a treatment of questionable benefit when compared to those who are 'pain free'. The study design deliberately eliminated the bias introduced into the decision-making process with the patient-physician interaction by using a standardized objective scenario outlining the treatment and a single measure of treatment acceptance.

\section{METHODS}

This study compared the strength of acceptance or rejection of a hypothetical, mock chronic pain treatment of debated value in two groups of patients: those reporting chronic noncancer pain and those who are reportedly 'pain free'. The Health and Research Ethics Board granted approval for the study. A questionnaire was distributed to: Group 1, patients attending the Multidisciplinary Chronic Pain Centre at the University of Alberta Hospital and Group 2, patients in the waiting room of the Grey Nuns Family Medicine Centre booked to see a family doctor. The questionnaire asked patients to score their personal 'treatment acceptance' of a hypothetical treatment for pain on a modified Likert scale $(-5$, strongly refuse to accept; +5 , strongly accept). The description of the treatment was based on published data regarding the risks and benefits of epidural steroids (3) (Figure 1). Inclusion criteria stipulated that patients should be between 18 and 66 years of age, and able to speak and understand English.

Many definitions of chronic pain involve complex multifaceted assessments $(8,9)$. It was decided to use a subjective, patient self-reported definition, ie, "severe and persistent pain for at least the last six months". The patients were asked to designate themselves to one of the following groups: A - had no pain problems over the last six months; $\mathrm{B}$ - had severe, persistent pain for at least six months; or $\mathrm{C}$ - do not come into either of the above two groups. Patients who classified themselves as Group B were asked to state how long they have suffered from pain. The patients were asked to score the pain they were currently suffering on a Numerical Rating Scale (NRS) zero to 10 (zero representing "no pain" and 10 representing "the most severe pain imaginable").

A previously described grading system for chronic pain estimated that $36.5 \%$ of the population is 'pain free' (10). Based on this estimate, a pilot study was completed with 20 patients in Group 1 and 60 in Group 2. The results of the pilot study confirmed that approximately one-third of patients (17 of 60 ) who were offered the questionnaire in the waiting room of the 


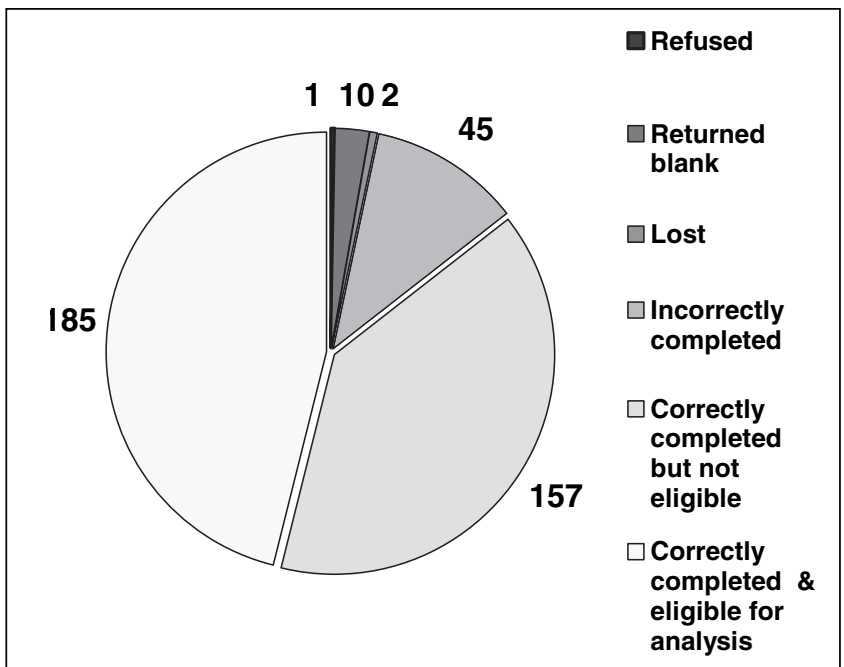

Figure 2) Outcome of all distributed questionnaires

TABLE 1

Analysis of responses in 'chronic pain' and 'pain free' group

\begin{tabular}{lcc}
\hline & \multicolumn{2}{c}{ Treatment acceptance } \\
\cline { 2 - 3 } & Median & Range \\
\hline Chronic pain group- Total & 3 & -5 to +5 \\
Pain free group - Total & 3 & -5 to +5 \\
Chronic pain group- Female & 3 & -5 to +5 \\
Pain free group -Female & 3 & -5 to +5 \\
Chronic pain group- Male & 4 & -5 to +5 \\
Pain free group - Male & 2.5 & -5 to +5 \\
\hline
\end{tabular}

Family Medicine Centre, were eligible to be included in our analysis as the 'pain free' group (self-designated to Group A on the questionnaire). Approximately one-half of patients (nine of 20) who were offered the questionnaire in the Chronic Pain Centre were eligible to be included in the analysis as the 'chronic pain' group (self-designated to Group B and scoring at least five on the NRS). An NRS score greater than five has been previously correlated with a verbal rating of 'severe' pain (11). Based on these proportions, the group sizes were calculated to yield comparable sized groups for the analysis.

It was agreed amongst the authors that a difference of two on the 'treatment acceptance' scale would be clinically meaningful. A power calculation was performed and indicated that in order to detect a difference of two on this scale, with $80 \%$ power, 60 participants would be required in each of the two study groups. The questionnaires and information letters were subsequently distributed to 160 consecutive patients in Group 1 (Chronic Pain Centre) and 240 in Group 2 (Family Practice Centre). All information was edited to achieve a Flesch Kincaid reading age of less than or equal to grade eight. The questionnaire contained a single, self-check item for understanding.

\section{RESULTS}

One patient refused to take part, 10 questionnaires were returned completely blank, and two were not returned and were considered 'lost'. Patients were eligible for inclusion in the analysis only if the questionnaire had been completely answered without error. Participants who had left blanks, failed

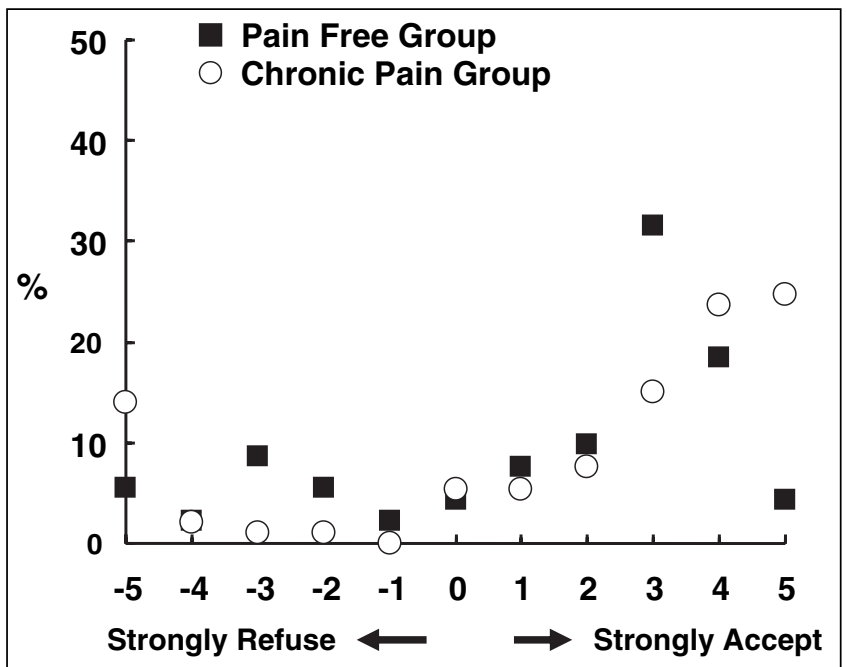

Figure 3) All patients treatment acceptance scores

TABLE 2

Analysis of length of pain history and numerical rating pain scores in the 'chronic pain' group

\begin{tabular}{ccccccc}
\hline & \multicolumn{3}{c}{ Years in pain } & & \multicolumn{2}{c}{ Pain score } \\
\cline { 2 - 4 } & Mean (SD) & Median & Range & & Median & Range \\
\hline Chronic pain group & $8.5(7.4)$ & 6.5 & 0.75 to 42 & & 7 & 5 to 10 \\
\hline
\end{tabular}

to answer questions or had answered with multiple responses were excluded. Twenty patients from the chronic pain centre and 25 patients from the family practice centre (14 in the 'chronic pain' group and 13 in the 'pain free' group), in total, had completed the questionnaires with errors and were therefore excluded. One-hundred-fifty-seven questionnaires were correctly completed, but were ineligible for inclusion in the analysis. Overall, 130 (81.25\%) of Group 1 questionnaires and $212(88.3 \%)$ of Group 2, were correctly completed. Ninetythree patients from Group 1 constituted the 'chronic pain' group and 92 patients from Group 2, the 'pain free' group (Figure 2). Both groups were comparable for age: the mean age was $42.2 \pm 10.4$ years (Mean \pm SD; range $=18-65$ ) and $43.3 \pm 11.9$ years (range $=19-65$ ) in the 'chronic pain' group and the 'pain free' group, respectively.

The median 'treatment acceptance' score for both groups was identical at +3 , (Table 1 and Figure 3 ). Fishers exact test was performed to analyze positive treatment acceptance scores versus responses zero and below. No significant differences at the $5 \%$ level were found comparing the 'chronic pain' and 'pain free' groups $(\mathrm{P}=0.5058)$. Additionally, no significant differences were found when male and female subgroups were analyzed in a similar manner (Figures 4 and 5).

There was a greater proportion of females in the 'pain free' group (Fisher's exact test, $\mathrm{P}=0.0221$ ). There were 42 males $(45.16 \%)$ and 51 females $(54.84 \%)$ in the 'chronic pain' group compared to 26 males $(28.26 \%)$ and 66 females $(71.74 \%)$ in the 'pain free' group.

The mean number of years that the 'chronic pain' group reported pain was $8.5 \pm 7.4$ years and the median pain score of this group at the time of the study was 7 (Table 2 ). 


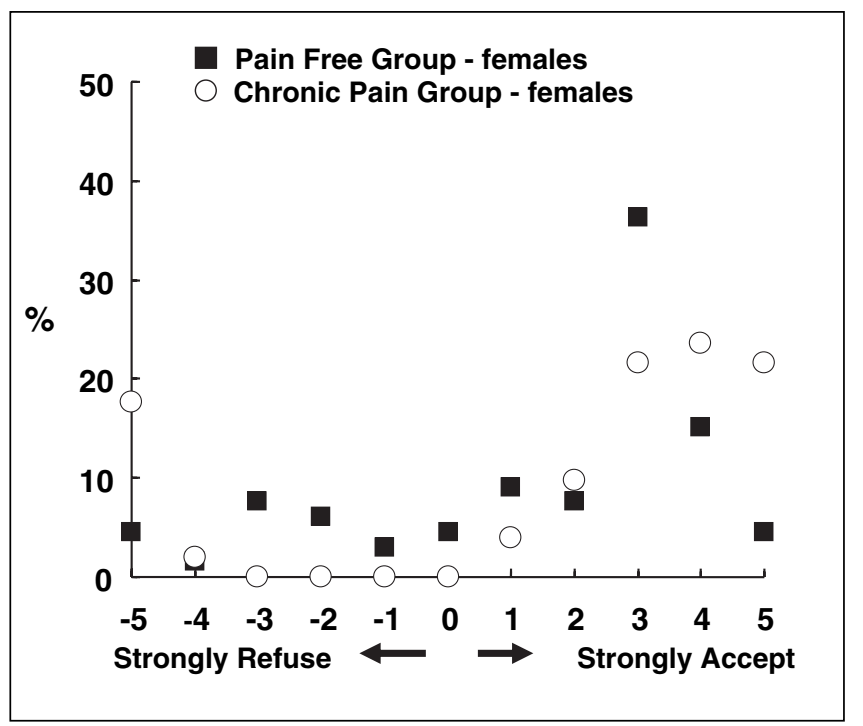

Figure 4) Treatment acceptance - females

\section{DISCUSSION}

There appears to be no significant difference between the two groups in terms of accurate completion and comprehension of the questionnaire. A similar number of patients from the 'chronic pain' group and 'pain free' group were excluded from the analysis for making written errors in their responses (14 and 13 patients, respectively). No patient in either group indicated that they did not understand the questionnaire.

The distribution of 'treatment acceptance' scores was visually similar in both groups. Both groups showed a tendency to accept the hypothetical treatment, but there was suggestion of a bimodal distribution with noticeable peaks of 'refusers' scoring -5 in the 'chronic pain' group and -3 in the 'pain free' group. This indicates reluctance on the part of some participants in both groups to accept the treatment, but particularly so in the 'chronic pain' group. One possibility is that this reflects a previous negative experience with chronic pain interventions (12). There was a higher proportion of females in the 'pain free' group, but the overall pattern of response of females is similar to that observed in males. The study design stipulated that a difference of two on the treatment acceptance scale would represent a meaningful clinical difference. It is noteworthy that median scores were identical in both groups at +3. This does not lend support to the hypothesis that the 'chronic pain' group has a greater tendency to accept the treatment. Nonparametric statistical testing revealed no significant difference between the groups in their acceptance of the treatment, and there appeared to be no significant sex difference in the readiness to accept the treatment of questionable benefit, although there was a loss of power when analyzing the sex subgroups.

It was not possible to disguise the mock treatment completely and some patients' responses may have been biased by the recognition of the treatment as an 'epidural steroid'. However, completely removing all potentially recognizable components of a hypothetical treatment runs the risk of presenting participants with no more than a numerical list of risks and benefits in an unrealistic scenario. Further studies could evaluate decision-making using multiple hypothetical scenarios with different treatment modalities.

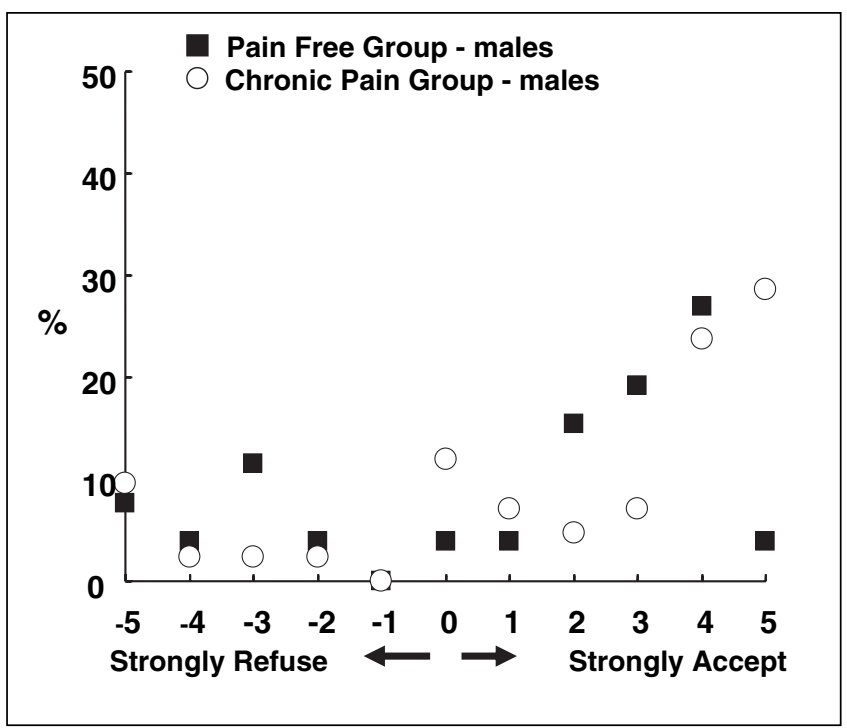

Figure 5) Treatment acceptance - males

It is a difficult task to measure a patient's willingness to accept treatment and/or risk entirely independent of the multiple influences that mould a clinical decision. This was a single item analogue study that did not, by design, examine actual clinical choices that patients make when confronted with real treatment options and is, therefore, subject to criticism, in this respect, as being unrealistic. However, the aim in using a written objective scenario was to reduce the bias introduced by clinical interaction with a physician and to objectively standardize the presentation of the information. When a patient is deciding on a real treatment option and discussing these choices with a physician, there is a host of variables and confounders that influence the outcome. One of the most significant influences is the physician's bias and personal agenda that may encompass the notion that questionable treatments can be justifiably offered to a chronic pain patient, for clinical or nonclinical reasons. Furthermore, a patient's decision-making may be swayed by a physician's financial agenda or considerations of cost-effectiveness (13). The quality and bias of any information presented by the physician will influence decision-making, and communication that promotes trust and confidence will also influence a patient's choice (14-16). Perceived risk, rather than the actual risk, may be more of an influence on a patient's eventual choice (17). It is an assumption that chronic pain sufferers are more inclined to accept risk because of their predicament, but we have no specific data to support this notion from this or previous studies.

The format and visual presentation of risk benefit data can affect patient acceptance or refusal of a treatment, and data should ideally be presented to patients in a variety of ways, eg, relative risk reduction, absolute risk difference and inverted absolute risk $(18,19)$. Patients may not fully understand numerical risk and some may prefer risk communication in terms of words $(20,21)$. We were reassured that the quality and amount of information given in our study questionnaire appeared to be far superior to the level of information that patients commonly receive in clinical practice (22).

Patient participation in decision-making is important, but it is often unclear how to evaluate a patient's level of readiness to participate in decision-making in the clinical setting 
$(23,24)$. Previous studies have indicated that patients have mixed preferences on the degree of physician direction and control in deciding treatment, ie, some patients prefer a shared approach and some prefer a directed approach, and this in turn is influenced variably by age and perceived chronic ill health (25). Our study design did not allow for participants to ask questions for clarification of information in the questionnaire itself and arguably some patients may have been pressed into making a treatment choice without the benefit of discussion with a physician. A further study examining treatment choices before and after discussion with a physician may yield useful information about the influence of the physician, but it would be necessary to independently assess the physician's attitude about offering questionable treatment.

Other factors more specific to chronic pain that could potentially influence treatment decisions are multiple and include the nature and severity of the condition, the length of time the patient has been in pain, the degree of psychosocial dysfunction and desperation, concurrent compensation and legal issues, and the need of the patient to validate their condition and placate the physician.

\section{REFERENCES}

1. Evidence-based medicine. A new approach to teaching the practice of medicine. Evidence Based Medicine Working Group. JAMA 1992;268:2420-5.

2. McQuay HJ, Moore RA, Eccleston C, Morley S, Williams AC. Systematic review of outpatient services for chronic pain control. Health Technol Assess 1997;1:1-135.

3. McQuay H, Moore A. Epidural steroids for sciatica. In: McQuay H, Moore A, eds. An evidence-based resource for pain relief. Oxford: Oxford University Press, 1998:216-8.

4. Bonica JJ, Loeser JD. History of pain concepts and therapies. In: Loeser JD, ed. Bonica's Management of Pain, 3rd edn. Philadelphia: Lippincott Williams \& Wilkins, 2001:3-16.

5. The Pain Society, the British Chapter of the International Association for the Study of Pain. Adult chronic pain management services in the United Kingdom. <www.painsociety.org/pdf/ dr_foster.pdf $>$ (Version current at April 13, 2004).

6. Patnaik A, Doyle C, Oza AM. Palliative therapy in advanced ovarian cancer: Balancing patient expectations, quality of life and cost. Anticancer drugs 1998;9:869-78.

7. Fitzgerald SP, Phillipov G. Patient attitudes to commonly promoted medical interventions. Med J Aust 2000;172:9-12.

8. Birse TM, Lander J. Prevalence of chronic pain. Can J Public Health 1998;89:129-31.

9. Verhaak PFM, Kerssens JJ, Dekker J, Sorbi MJ, Bensing JM. Prevalence of chronic benign pain disorder among adults: A review of the literature. Pain 1998;77:231-9.

10. Von Korff M, Dworkin SF, Le Resche L. Graded chronic pain status: An epidemiologic evaluation. Pain 1990;40:279-91.

11. McQuay H, Moore A. Pain measurement, study design and validity. In: McQuay H, Moore A, eds. An evidence based resource for pain relief. Oxford: Oxford University Press, 1998:14-8.

12. Pattenden J, Watt I, Lewin RJ, Stanford N. Decision making processes in people with symptoms of acute myocardial infarction: Qualitative study. BMJ 2002;324:1006-9.

13. Raab SS, Hornberger J. The effect of a patient's risk taking attitude on cost effectiveness of testing strategies in the evaluation of pulmonary lesions. Chest 1997;111:1583-90.
As health professionals, we are obliged to provide treatment that has been demonstrated to be effective and safe. When caring for patients in pain, it will be helpful to be forearmed with knowledge of what influences treatment decisions. We conclude that this study does not support the hypothesis that patients with chronic noncancer pain accept treatment of questionable benefit more readily than those who are 'pain free'. It would appear that both groups have a tendency to accept the treatment to a similar degree. We argue that it is necessary to embark on future studies to clarify the complex factors that impact on decision-making in the chronic pain population.

ACKNOWLEDGEMENTS: The contributions of Kathryn Jamieson BSc, Department of Anesthesia and Pain Medicine, Faculty of Medicine and Dentistry, University of Alberta Edmonton, Alberta and the reception staff at The Grey Nuns Family Medicine Centre, Grey Nuns Hospital, Cedars Professional Park, 2927 66th Street, Edmonton, Alberta for administering the study questionnaires are acknowledged.

14. Slaytor EK, Ward JE. How risks of breast cancer and benefits of screening are communicated to women: Analysis of 58 pamphlets. BMJ 1998;317:263-4.

15. Domenighetti G, Grilli R, Maggi JR. Does provision of an evidence based information change public willingness to accept screening tests? Health Expect 2000;3:145-50.

16. Jenkins V, Fallowfield L. Reasons for accepting or declining to participate in randomized clinical trials for cancer therapy. Br J Cancer 2000;82:1783-8.

17. Marteau TM, Kidd J, Cook R, et al. Perceived risk not actual risk predicts uptake of amniocentesis. Br J Obstet Gynaecol 1991;98:282-6.

18. Hux JE, Naylor CD. Communicating the benefits of chronic preventative therapy: Does the format of efficacy data determine patients' acceptance of treatment? Med Decis Making 1995; 15:152-7.

19. Feldman-Stewart D, Kocovski N, McConnell BA, Brundage MD, Mackillop WJ. Perception of quantative information for treatment. Med Decis Making 2000;20:228-38.

20. Schwartz LM, Woloshin S, Black WC, Welch HG. The role of numeracy in understanding the benefit of screening mammography. Ann Intern Med 1997;127:966-72.

21. Mazur DJ, Hickam DH, Mazur MD. How patients' preferences for risk information influence treatment choice in a case of high risk and high therapeutic uncertainty: Asymptomatic localized prostate cancer. Med Decis Making 1999;19:394-8.

22. Braddock CH, Fihn SD, Levinson WL, Jonsen AR, Pearlman RA. How doctors and patients discuss routine clinical decisions. Informed decision making in the out-patient setting. J Gen Intern Med 1997;12:339-45.

23. Craig YJ. Patient decision-making: Medical ethics and mediation. J Med Ethics 1996;22:164-7.

24. Guadagnoli E, Ward P. Patient participation in decision making. Soc Sci Med 1998;47:329-39.

25. McKinstry B. Do patients wish to be involved in decision making in the consultation? A cross sectional survey with video vignettes. BMJ 2000;321:867-71. 


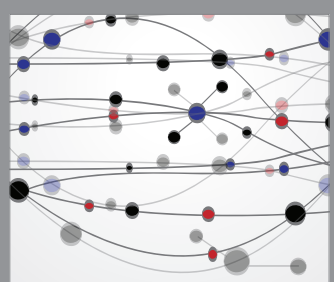

The Scientific World Journal
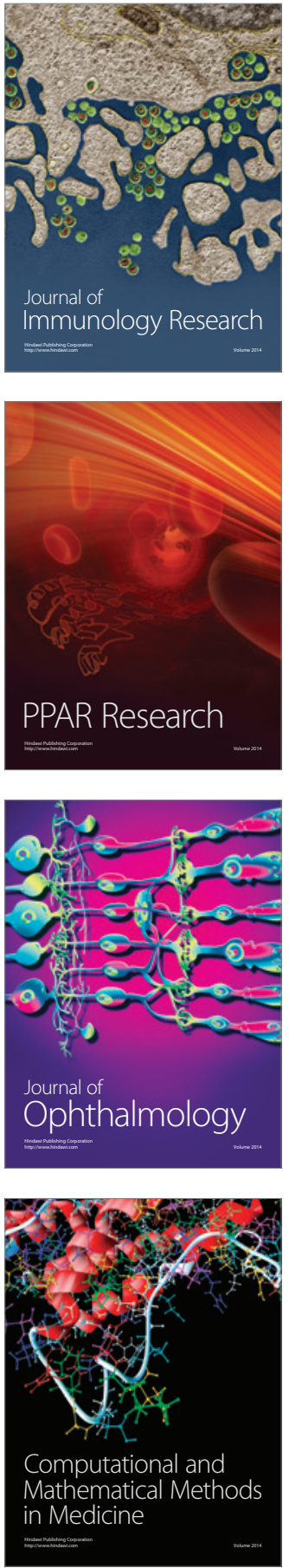

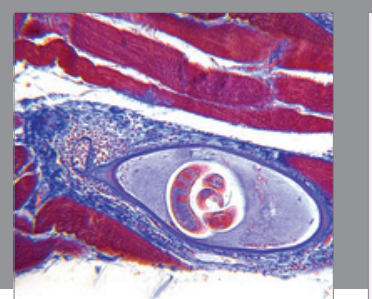

Gastroenterology Research and Practice

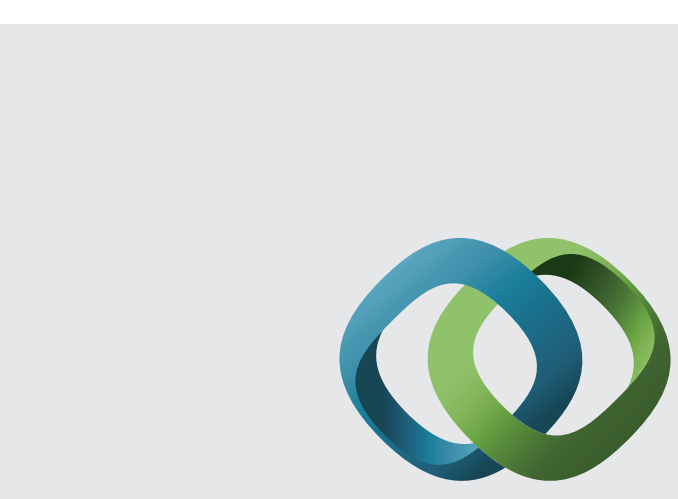

\section{Hindawi}

Submit your manuscripts at

http://www.hindawi.com
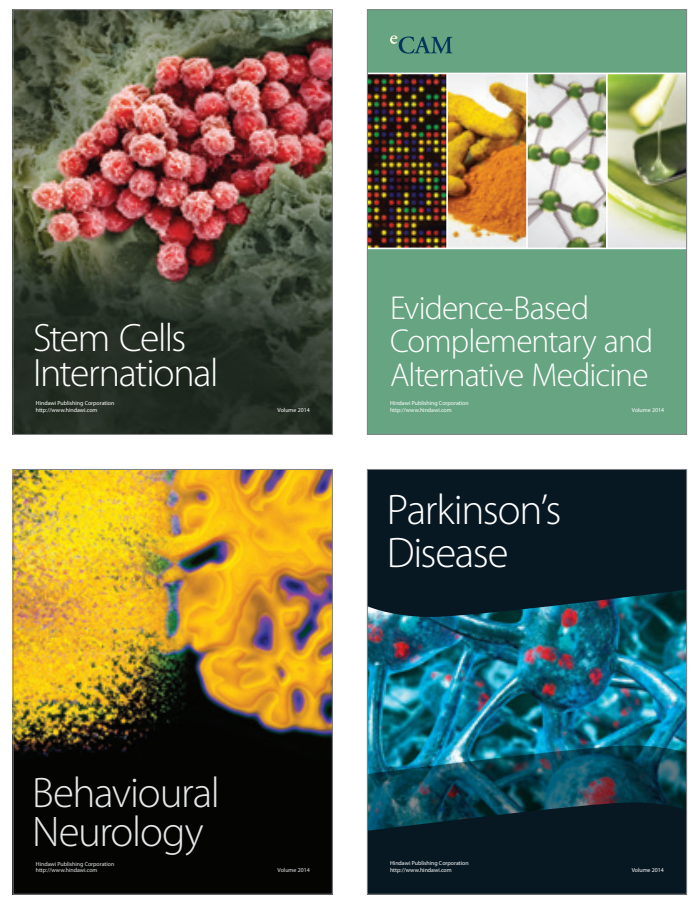
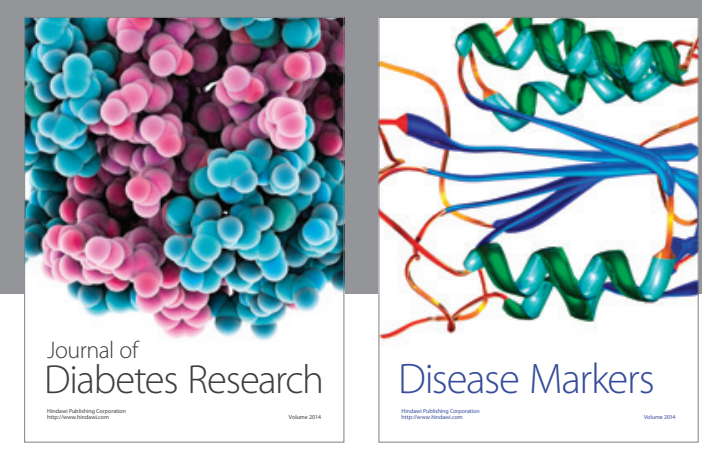

Disease Markers
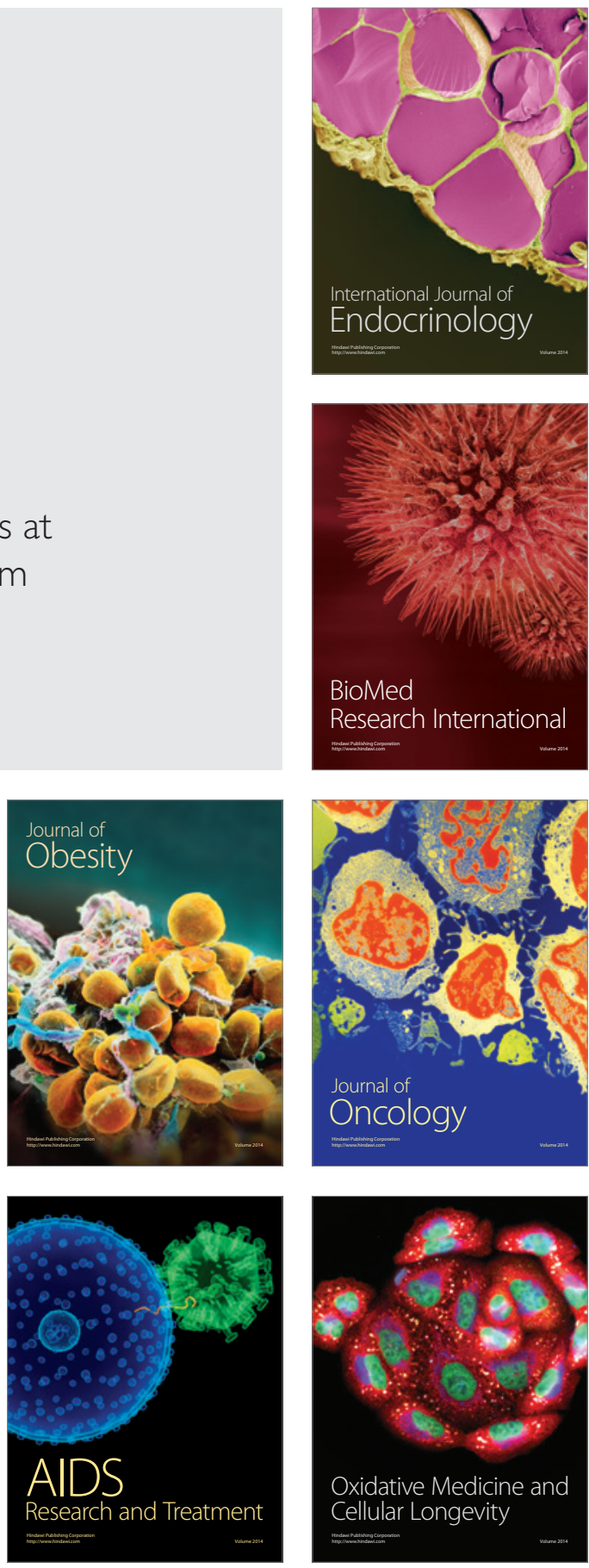